\title{
The prebiotic effects of biscuits containing partially hydrolysed guar gum and fructo-oligosaccharides - a human volunteer study
}

\author{
K. M. Tuohy ${ }^{1}$, S. Kolida ${ }^{1}$, A. M. Lustenberger ${ }^{2}$ and G. R. Gibson ${ }^{1}$ \\ ${ }^{1}$ Food Microbial Sciences Unit, School of Food Biosciences, The University of Reading, Reading RG6 6AP, UK \\ ${ }^{2}$ Novartis Nutrition Research AG, 3176 Neuenegg, Switzerland
}

(Received 3 August 2000 - Revised 26 January 2001 - Accepted 12 March 2001)

\begin{abstract}
Prebiotics are non-digestible food ingredients that target selected groups of the human colonic microflora, thus having the ability to alter the composition towards a more 'beneficial' community, i.e. selectively increasing populations of bifidobacteria and/or lactobacilli. In the present study the prebiotic potential of partially hydrolysed guar gum (PHGG) and fructooligosaccharides (FOS) in a biscuit was assessed in human volunteers. Fluorescent in situ hybridization using oligonucleotide probes targeting Bacteroides spp., Bifidobacterium spp., Clostridium spp. and Lactobacillus-Enterococcus spp. were used for the bacteriology and total bacteria were enumerated using the fluorescent stain 4',6-diamidino-2-phenylindole. Thirty-one volunteers consumed daily either three experimental biscuits (providing a total $(\mathrm{g} / \mathrm{d})$ of $6.6 \mathrm{FOS}$ and 3.4 PHGG) or three placebo biscuits for two 21-d crossover periods. Bifidobacteria significantly increased in number on ingestion of the experimental biscuits compared with pretreatment and placebo population levels. Bifidobacterial numbers returned to pretreatment levels within $7 \mathrm{~d}$ of the cessation of intake of experimental biscuits. A correlation was observed between the initial faecal bifidobacterial numbers and the magnitude of bifidogenesis, with volunteers who possessed low initial population levels of bifidobacteria experiencing the greatest increase in bifidogenesis. No changes were observed in the other bacterial groups monitored during the trial. Thus, the prebiotic nature of FOS and PHGG was maintained in a final food product as evidenced from the selective increase in bifidobacterial numbers.
\end{abstract}

\section{Gut microflora: Prebiotic: Gene probes}

The importance of the human colon in health and disease has become increasingly recognized with a greater understanding of the ecology and biological importance of the human gastrointestinal microflora. More than 500 different bacterial species are thought to make up the gut microbiota, with the total number of bacterial cells present in the colon far exceeding the total number of eukaryotic cells in the body (Conway, 1995; Gibson \& Beaumont, 1996; Tannock, 1999). Although it is known that many disease states involve bacterial metabolism, the human gut microflora may also be considered as very relevant to improved host health (Gibson \& Beaumont, 1996). For instance, bifidobacteria and lactobacilli are thought to improve resistance to gut infections by inhibiting the growth of harmful bacteria, to reduce cholesterol levels, to improve the immune response and to produce vitamins (Gibson, 1998; Holzapfel et al. 1998; Vanderhoof \& Young, 1998; Ziemer \& Gibson, 1998). In the present study the efficacy of biscuits containing fructo-oligosaccharides (FOS) and partially hydrolysed guar gum (PHGG) in bringing about a beneficial modulation of the gastrointestinal microflora was determined. Particularly, the ability of the prebiotic biscuits to increase numbers of bifidobacteria selectively was assessed.

The complexity of the gut microflora presents difficulties in monitoring this ecological phenomenon (Steer et al. 2000). Selective agars and growth conditions exist for only a small percentage of the most numerically dominant species, and it has been estimated that only between 10 and $50 \%$ of bacteria present in the human gut have been cultivated (Langendijk et al. 1995; Wilson \& Blitchington, 1996). The phylogenetic information encoded by $16 \mathrm{~S}$ rRNA has enabled the development of molecular biology techniques to allow characterization of the whole human gut microflora (Collins \& Gibson, 1999; Suau et al. 1999). Similarly, fluorescent in situ hybridization (FISH), employing

Abbreviations: FISH, fluorescent in situ hybridization; FOS, fructo-oligosaccharides; PHGG, partially hydrolysed guar gum.

* Corresponding author: Kieran Tuohy, fax +44 118 9357222, email k.m.tuohy@reading.ac.uk 
oligonucleotide probes targeting 16S rRNA, allows the enumeration of both culturable and non-culturable moieties of the gut microflora in situ in gastrointestinal and faecal samples (Amann et al. 1995; Langendijk et al. 1995; Zoetendal et al. 1998; Ames et al. 1999). Using FISH, changes in population levels of specific phylogenetically related groups of bacteria may be monitored in response to altering ecological conditions, such as the presence of fermentable substrate.

Manipulation of the gut microflora for improved health is not a new concept. Probiotics, which are live microbial feed additives thought to confer health advantages, have a long history (Fuller \& Gibson, 1997). Whilst the probiotic approach is conceptually sound, it does have problems in practice. Many of the health-promoting attributes of selected probiotic strains may be determined by survival of relatively high numbers $\left(>10^{7}\right.$ colony-forming units $/ \mathrm{ml}$ lumen contents) of metabolically active cells in the human colon (Ducluzeau, 1989). The disparity in scientific reports investigating the health benefits of probiotics in human studies may at least in part be related to survivability problems of the probiotic strain in the product, but mainly after ingestion (MacFarlane \& Gibson, 1997; Roberfroid et al. 1998; Collins \& Gibson, 1999). Prebiotics are nondigestible food ingredients that beneficially affect the host by selectively stimulating the growth and/or activity of one or a limited number of bacteria in the colon that can improve host health (Gibson \& Roberfroid, 1995). Efficient prebiotics need to induce a specific fermentation in the colon. This process should occur by the stimulation of benign, or potentially health-promoting, indigenous bacterial genera but not harmful organisms (Gibson \& Roberfroid, 1995). The premise is therefore similar to that of dietary fibres, but with a much more tailored fermentation, e.g. towards lactic acid-producing bacteria (Gibson et al. 1996; Collins \& Gibson, 1999).

The identification of potential prebiotics is of considerable scientific and commercial interest. FOS are most commonly thought of as prebiotics and occur naturally in onion (Allium cepa), asparagus (Asparagus officinatis) and artichoke (Cynara scolymus). They are poorly digested in the human small intestine, but are fermented in the colon by the resident microflora (Andersson et al. 1999). In vivo human studies have shown that dietary addition of FOS leads to an increase in faecal bifidobacteria (Gibson et al. 1995; Roberfroid et al. 1998; Bouhnik et al. 1999). However, such studies were conducted using FOS as a dietary supplement. There is no information on the prebiotic capabilities of FOS present in a processed or final food product consumed as part of the daily diet. Guar gum is a soluble fibre derived from the Indian cluster bean (Cyamopsis tetragonoloba ( psoralioides)); it forms viscous solutions and is used worldwide in the food industry as a thickener and emulsion stabilizer. Partially hydrolysing the guar gum causes its viscous consistency to be lost, so that it can be added to food in high amounts. It has been shown that PHGG has a positive effect on diarrhoea, e.g. reducing its duration (Alam et al. 1997) or incidence (Homann et al. 1994), as well as having an ameliorating effect in human subjects suffering from constipation (Takahashi et al. 1994). Similarly, Okubo et al. (1994) have demonstrated that ingestion of PHGG at $21 \mathrm{~g} / \mathrm{d}$ for $14 \mathrm{~d}$ resulted in a small increase in bifidobacteria and a sizable increase in lactobacilli in faecal samples collected from nine healthy male volunteers. This response occurred despite the fact that neither bifidobacteria nor lactobacilli were able to grow in vitro using $\mathrm{PHGG}$ as the only $\mathrm{C}$ source. The addition of fermentable fibre $(21 \mathrm{~g} / \mathrm{d})$ into the colon represents a considerable contribution to the total carbohydrate load available to bacteria in the colon, estimated to be between 40 and $60 \mathrm{~g} / \mathrm{d}$ (Hudson \& Marsh, 1995). Little is known about the prebiotic capabilities of PHGG when delivered into the colon at lower doses.

To date, no data exist on the prebiotic effects of a final food product containing FOS. Here we determined in a human volunteer study the prebiotic potential of PHGG and FOS incorporated into a biscuit. To overcome the limitations of traditional microbiological culture in the recovery and enumeration of specific groups of bacteria, FISH employing 16S rRNA-targeted probes was used for the bacteriology.

\section{Experimental design \\ Experimental treatment}

Experimental biscuits provided $6.6 \mathrm{~g}$ FOS/d and $3.4 \mathrm{~g}$ PHGG/d. Active treatment was delivered as three biscuits $(37.5 \mathrm{~g})$ daily, containing (w/v): wheat flour $40 \%$, sugar $5 \%$, vegetable fat $15 \%$, FOS $20 \%$, PHGG $11 \%$, wheat flakes $6 \%$, baking powder $1 \%$, salt $0 \cdot 2 \%$. Volunteers were free to eat the biscuits at any time of day.

\section{Placebo treatment}

Placebo treatment did not contain FOS or PHGG and was delivered as three biscuits daily, containing (w/v): wheat flour $60 \%$, sugar $12 \%$, vegetable fat $15 \%$, wheat flakes $6 \%$, baking powder $1 \%$, salt $0.2 \%$.

Biscuits were supplied by Novartis Nutrition Research AG, Neuenegg, Switzerland and colour coded (experimental or placebo) so as to be blind to investigator as well as volunteers. Volunteers consumed experimental biscuits for one $21 \mathrm{~d}$ period and the placebo biscuits for a second $21 \mathrm{~d}$ period, i.e. the trial was conducted with a crossover between experimental and placebo treatments. Volunteers were randomly chosen to consume either the experimental or the placebo biscuits during the first treatment. Sixteen volunteers consumed the experimental biscuits during the second treatment. Volunteers were asked to keep diaries while ingesting biscuits, to record stool frequency and consistency (constipation, hard, formed, soft or diarrhoea), abdominal pain (none, mild, moderate or severe), intestinal bloating (none, mild, moderate or severe) and flatulence (none, mild, moderate or severe) on a daily basis. Any concomitant medication, adverse events or volunteer comments were also recorded.

\section{Outline of study protocol}

Subjects. Thirty-one healthy volunteers (seventeen females, fourteen males) participated in the present study. Written 
consent was obtained from each individual and the study was approved by the Ethics Committee of the University of Reading. Test biscuits were administered to volunteers at the start of each $21 \mathrm{~d}$ treatment period. Volunteers were asked to eat three biscuits daily, and were free to consume the biscuits at any time during the day. Volunteers were asked to return any uneaten biscuits. There was a high level of compliance (judged to be at least $90 \%$ ) with only a few volunteers returning one or two packets of biscuits.

Pretrial assessment. Volunteers were assessed for good health and selected on the basis of adherence to inclusion or exclusion criteria. Two pretreatment stool samples were taken, between day -3 and 0 .

Treatment 1 (days 1-21). Volunteers consumed biscuits (experimental or placebo) and kept diaries during treatment 1. Stool samples were obtained on two consecutive days starting on day 19, 20, 21 or 22.

Treatment 2 (days 23-44). Volunteers consumed a second set of biscuits (experimental or placebo) and kept diaries during treatment 2. Stool samples were obtained on two consecutive days starting on day 40, 41, 42 or 43.

Volunteers returned unused biscuits and completed diaries.

Post-treatment sampling (days 49, 56 and 63). Single post-treatment stool samples were obtained on day 47, 48, 49,50 or 51 and on day $54,55,56,57$ or 58 . Two stool samples were obtained, on two consecutive days starting on day $61,62,63$ or 64 .

\section{Inclusion and exclusion criteria}

Inclusion criteria. The criteria were: signed consent form, age $18-50$ years inclusive, BMI $20-30 \mathrm{~kg} / \mathrm{m}^{2}$ inclusive and good general health as determined by a medical questionnaire.

Exclusion criteria. Volunteers were excluded from the trial if there was evidence of physical or mental disease or major surgery, as revealed by medical history, that might limit participation in or completion of the study. Volunteers with a history of drug abuse, including alcohol, were excluded. Volunteers were excluded if they were pregnant, lactating or planning pregnancy, had severe allergy or a history of a severe abnormal drug reaction. Other exclusion criteria included: participation in a clinical trial (e.g. for an experimental drug) within 4 weeks before the study, former participation in a prebiotic or laxative trial within the previous 3 months, use of antibiotics within the previous 6 months, chronic constipation, diarrhoea or other chronic gastrointestinal complaints, and intake of other specific prebiotics or probiotics, drugs active on gastrointestinal motility, or a laxative of any class, for 4 weeks before the study.

Requirements for diet and medication during the study. The following were not permitted: intake of additional prebiotics (such as oligosaccharides, e.g. FOS or inulin), probiotics, live yoghurts, drugs active on gastrointestinal motility, antibiotic treatment or any class of laxative. Any medication taken was recorded in diaries. Volunteers were instructed not to alter their usual diet or fluid intake during the trial period.

\section{Bacterial enumeration}

Faecal samples were collected in sterile plastic pots and stored at $4^{\circ} \mathrm{C}$, and processed within $2 \mathrm{~h}$ of collection. Freshly voided faecal samples were diluted 1:10 (w/w) with phosphate buffer $(0 \cdot 1 \mathrm{M}$; $\mathrm{pH} 7 \cdot 0)$ and mixed in a stomacher for $2 \mathrm{~min}$. Changes in faecal bacterial populations were assessed through the use of FISH with molecular probes targeting 16S rRNA. Genotypic probes targeting predominant components of the gut microflora (bacteroides, bifidobacteria, clostridia and lactobacilli) were manufactured and tagged with fluorescent markers so that quantifiable changes in faecal bacterial populations were determined. The probes used were Bif164 (Langendijk et al. 1995), Bac303 (Manz et al. 1996), His150 (Franks et al. 1998) and Lab158 5'GGTATTAGCA(T/C)CTGTTTCCA (Harmsen et al. 1999), specific for bifidobacteria, bacteroides, clostridia (Clostridium perfringens/histolyticum sub.grp.) and Lactobacillus-Enterococcus spp. respectively. The nucleic acid stain 4'6-diamidino-2-phenylindole was used for total bacterial counts. Faecal samples were diluted and fixed overnight in paraformaldehyde. These cells were then washed with phosphate-buffered saline $(0 \cdot 1 \mathrm{M}-\mathrm{NaCl} ; \mathrm{pH} 7 \cdot 0)$, resuspended and stored at $-20^{\circ} \mathrm{C}$. The cell suspension was then added to the hybridization mixture. Hybridization was carried out at appropriate temperatures for the probes. Subsequently, the hybridization mix was vacuum filtered and the filter was mounted onto a microscope slide and examined under a fluorescent microscope. The significance of changes in bacterial numbers measured on ingestion of experimental biscuits compared with bacterial numbers at pretreatment, after ingestion of placebo biscuits, 7 and $14 \mathrm{~d}$ after cessation of the intake of experimental biscuits and return to pretreatment population levels, were assessed using the matched paired $t$ test.

\section{Results \\ Bacteriology}

Bacterial populations present in the thirty-one volunteers over the experimental period are shown in Table 1. Bacterial counts were determined using FISH and are expressed as $\log _{10}$ cells/g faeces. No significant difference was observed in the numbers of total bacteria, Bacteroides spp., Clostridium spp. or Lactobacillus spp. on ingestion of either experimental or placebo biscuits. However, consumption of experimental biscuits resulted in an increase in bifidobacterial numbers of $0.487 \log _{10}$ cells/g faeces from pretreatment levels. A significant increase in Bifidobacterium spp. was observed on ingestion of experimental biscuits compared with ingestion of the placebo biscuits $(P=$ $\left.2 \cdot 15 \times 10^{-5}\right)$. Bifidobacterial numbers increased from pretreatment levels of $9 \cdot 10 \log _{10}$ cells/g faeces and placebo levels of $9.18 \log _{10}$ cells/g faeces, to $9.59 \log _{10}$ cells/g faeces after ingestion of the experimental biscuits.

In the sixteen volunteers who ingested experimental biscuits during the second treatment, no significant difference was observed between bifidobacterial numbers $7 \mathrm{~d}$ after cessation of treatment or from pretreatment population levels (Table 2). A bifidobacterial population 
Table 1. Faecal bacterial numbers ( $\log _{10}$ cells/g faeces) determined by fluorescent in situ hybridization for thirty-one volunteers over the trial period during which they were given placebo biscuits or experimental biscuits containing partially hydrolysed guar gum and fructo-oligosaccharides $\dagger$

(Mean values and standard deviations)

\begin{tabular}{|c|c|c|c|c|c|c|c|c|}
\hline \multirow{2}{*}{$\begin{array}{l}\text { Treatment group } \neq . . . \\
\text { Bacterial group }\end{array}$} & \multicolumn{2}{|c|}{ Pretreatment } & \multicolumn{2}{|c|}{ Placebo } & \multicolumn{2}{|c|}{ Experimental } & \multicolumn{2}{|c|}{ Post-treatment } \\
\hline & Mean & SD & Mean & SD & Mean & SD & Mean & SD \\
\hline Total bacteria & $10 \cdot 60$ & 0.22 & $10 \cdot 61$ & $0 \cdot 21$ & $10 \cdot 68$ & 0.22 & $10 \cdot 62 \S$ & 0.44 \\
\hline Bacteroides spp. & $9 \cdot 76$ & 0.24 & 9.67 & 0.30 & $9 \cdot 71$ & 0.32 & $9 \cdot 71 \S$ & 0.36 \\
\hline Bifidobacterium spp. & $9 \cdot 10$ & 0.42 & $9 \cdot 18$ & 0.51 & $9 \cdot 59^{*}$ & 0.26 & $8.98 \S$ & 0.41 \\
\hline Clostridium spp. & 7.93 & 0.89 & $7 \cdot 81$ & 0.79 & $7 \cdot 76$ & 0.73 & $7 \cdot 68 \S$ & 0.51 \\
\hline Lactobacillus spp. & $7 \cdot 71$ & 0.44 & $7 \cdot 71$ & 0.38 & $7 \cdot 72$ & 0.55 & $7 \cdot 62 \S$ & 0.43 \\
\hline
\end{tabular}

Mean value was significantly different from that for the placebo group (paired $t$ test): ${ }^{*} P=2 \cdot 15 \times 10^{-5}$

tFor details of subjects and procedures, see p. 342 .

$\ddagger$ Stool samples were collected at time points between days -14 and 0 (pretreatment), days 0 and 19-23 (placebo), days 19-23 and 40-44 (experimental) and days 61-65 (post-treatment).

$\S$ Mean values were not significantly different from those for the pretreatment group.

level of $9.55 \log _{10}$ cells/g faeces after experimental treatment decreased to $9.08 \log _{10}$ cells/g on day 7 after the end of intake of experimental biscuits. Clearly, bifidobacterial population levels returned to approximately pretreatment levels once volunteers stopped eating the experimental biscuits (or at least within $7 \mathrm{~d}$ after experimental treatment ceased).

Not all the volunteers responded in a similar manner to ingestion of the experimental biscuits. Fig. 1 correlates the change in bifidobacterial population levels observed in faecal samples with the initial numbers for the thirty-one volunteers. Those volunteers showing the lowest initial bifidobacterial population levels gave the largest increase on ingestion of the experimental biscuits. Fifteen of the volunteers gave increases in bifidobacterial number of $\geq 0 \cdot 5$ $\log _{10}$ cells/g faeces, twelve gave increases of $<0 \cdot 5 \log _{10}$ cells/g faeces and in four volunteers bifidobacteria number decreased after ingestion of the experimental biscuits (Fig. 1). In volunteers showing initial bifidobacterial levels of $\geq 9.45 \log _{10}$ cells/g faeces, no major change in number was observed after ingestion of the experimental biscuits. Overall, bifidobacteria increased in number by more than $0.2 \log _{10}$ cells $/ \mathrm{g}$ faeces in $70 \%$ of the volunteers. Little or no change in numbers of total bacteria, Bacteroides spp., Clostridium spp. or Lactobacillus-Enterococcus spp. was observed when data from this group were analysed separately.

\section{Gastrointestinal symptoms and digestive tolerance}

Faecal $\mathrm{pH}$ changed little during the trial period. Mean faecal $\mathrm{pH}$ for the thirty-one volunteers was $6.96,7.08$ and 7.05 for pretreatment, placebo treatment and experimental treatment faecal samples respectively. Similarly, no significant difference was observed in mean daily stool frequency, which was 1.61 (SD 0.94; $n$ 31) during placebo treatment and 1.59 (SD $0.67 ; n$ 31) during experimental treatment. Some volunteers did report increased occurrence of soft stools during the first few days of intake of experimental biscuits.

Table 3 summarizes data on digestive tolerance (flatulence, abdominal pain, bloating) and stool consistency recorded by volunteers during biscuit intake. Stool consistency, qualitatively graded by volunteers as constipation, hard, formed, soft or diarrhoea, varied greatly between individuals. The percentage coverage of each category over the total number of responses given per volunteer was determined. Ingestion of the placebo biscuits gave a small increase in the percentage of stools described as formed-constipation. Stools during experimental biscuit intake were more often described as formed-soft. This description was especially true of stool samples collected during the first few days of ingestion of experimental biscuits. The occurrence of abdominal pain, intestinal bloating and flatulence were also qualitatively recorded daily by volunteers in diaries under the categories none,

Table 2. Bifidobacterium spp. population levels ( $\log _{10}$ cells $/ g$ faeces) determined by fluorescent in situ hybridization in sixteen volunteers given experimental biscuits containing partially hydrolysed guar gum and fructo-oligosaccharides during the second treatment (T2) stage* $^{*}$

(Mean values and standard deviations)

\begin{tabular}{|c|c|c|c|c|c|c|c|c|c|}
\hline \multicolumn{2}{|c|}{ Pretreatment } & \multicolumn{2}{|c|}{$\begin{array}{l}\text { Experimental } \\
\text { treatment (T2) }\end{array}$} & \multicolumn{2}{|c|}{$\mathrm{T} 2+7 \mathrm{~d}$} & \multicolumn{2}{|c|}{$\mathrm{T} 2+14 \mathrm{~d}$} & \multicolumn{2}{|c|}{$\begin{array}{l}\text { Return to } \\
\text { pretreatment }\end{array}$} \\
\hline Mean & SD & Mean & SD & Mean & SD & Mean & SD & Mean & SD \\
\hline $8 \cdot 98^{a}$ & 0.49 & $9 \cdot 55^{\mathrm{b}}$ & 0.25 & $9 \cdot 08^{a}$ & 0.45 & $8 \cdot 83^{a}$ & 0.72 & $8.91 \dagger$ & 0.50 \\
\hline
\end{tabular}




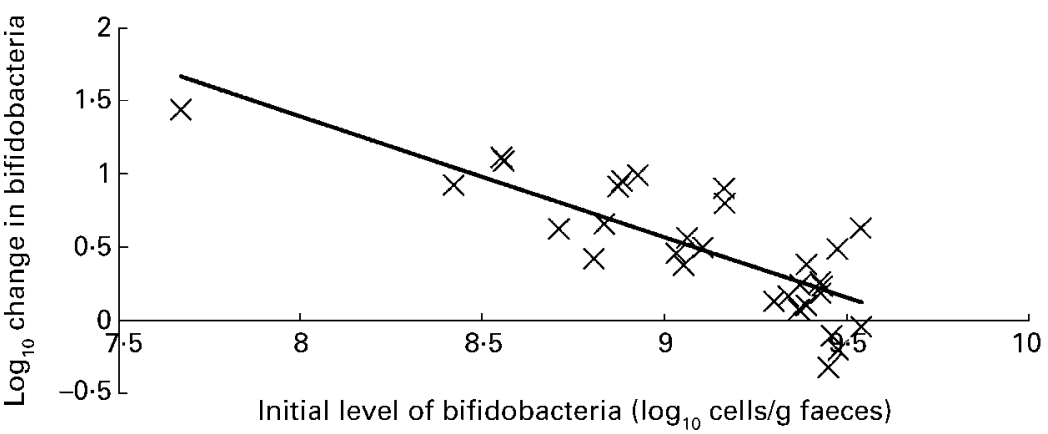

Fig. 1. Increase in bifidobacterial numbers in stool samples collected from thirtyone volunteers as a function of initial pretreatment bifidobacterial population levels. Bacterial counts are expressed as $\log _{10}$ cells/g faeces (mean of two samples) and were determined using fluorescent in situ hybridization. The line of best fit through the data $\left(R^{2} 0.6465\right)$ shows that volunteers with the lowest initial levels of bifidobacteria gave the largest increase in bifidobacterial numbers on ingestion of the experimental biscuits containing partially hydrolysed guar gum and fructo-oligosaccharides.

mild, moderate and severe. The percentage coverage of each category over the total number of responses given by each volunteer was determined (Table 3). As with stool consistency, the range and frequency of responses given by different volunteers varied greatly. During experimental treatment, a small increase in mild $(6.09 \%)$ and moderate $(7 \cdot 28 \%)$ abdominal pain was reported. There was also a general trend towards a reporting of flatulence and intestinal bloating as moderate during consumption of

Table 3. Summary of data recorded* in diaries by thirty-one volunteers over the course of the trial of intake of placebo biscuits or experimental biscuits containing partially hydrolysed guar gum and fructo-oligosaccharides $†$

(Mean values and standard deviations)

\begin{tabular}{|c|c|c|c|c|}
\hline \multirow[t]{2}{*}{ Treatment group... } & \multicolumn{2}{|c|}{ Placebo } & \multicolumn{2}{|c|}{ Experimental } \\
\hline & Mean & SD & Mean & SD \\
\hline \multicolumn{5}{|l|}{ Stool consistency } \\
\hline Constipation & 30.95 & $10 \cdot 11$ & $14 \cdot 46$ & $11 \cdot 88$ \\
\hline Hard & $17 \cdot 87$ & 9.94 & $12 \cdot 03$ & $8 \cdot 75$ \\
\hline Formed & $70 \cdot 78$ & 28.43 & $63 \cdot 15$ & 23.98 \\
\hline Soft & 31.40 & $29 \cdot 41$ & 31.05 & 24.71 \\
\hline Diarrhoea & 8.33 & 5.59 & $7 \cdot 66$ & 3.79 \\
\hline \multicolumn{5}{|l|}{ Digestive tolerance } \\
\hline \multicolumn{5}{|l|}{ Abdominal pain } \\
\hline None & 89.04 & $15 \cdot 76$ & $77 \cdot 16$ & $23 \cdot 64$ \\
\hline Mild & $15 \cdot 34$ & 11.58 & 21.43 & 18.87 \\
\hline Moderate & $10 \cdot 57$ & 7.51 & $17 \cdot 85$ & $22 \cdot 62$ \\
\hline Severe & $5 \cdot 3$ & & $13 \cdot 6$ & \\
\hline \multicolumn{5}{|l|}{ Intestinal bloating } \\
\hline None & 80.95 & $25 \cdot 44$ & $64 \cdot 21$ & 30.91 \\
\hline Mild & $32 \cdot 70$ & $28 \cdot 25$ & $32 \cdot 30$ & $21 \cdot 30$ \\
\hline Moderate & $15 \cdot 38$ & $12 \cdot 63$ & $20 \cdot 47$ & $19 \cdot 58$ \\
\hline Severe & - & - & $18 \cdot 38$ & $24 \cdot 00$ \\
\hline \multicolumn{5}{|l|}{ Flatulence } \\
\hline None & $60 \cdot 11$ & 29.51 & 42.92 & 33.48 \\
\hline Mild & 51.35 & 27.91 & $43 \cdot 30$ & $22 \cdot 96$ \\
\hline Moderate & $18 \cdot 38$ & $12 \cdot 01$ & $29 \cdot 22$ & $15 \cdot 78$ \\
\hline Severe & $6 \cdot 75$ & $2 \cdot 76$ & $15 \cdot 71$ & $20 \cdot 53$ \\
\hline
\end{tabular}

* Percentage coverage of each category over the total number of responses given per volunteer was determined.

†For details of subjects and procedures, see p. 342. experimental biscuits compared with mild during placebo ingestion. Only two volunteers reported any severe or significant increase in flatulence (and intestinal bloating in one of these volunteers) during ingestion of experimental biscuits.

Moderate and severe intestinal bloating increased by 5.09 and $18.38 \%$ respectively, during experimental treatment compared with placebo treatment. Moderate and severe flatulence increased by 10.84 and $8.96 \%$ respectively during ingestion of the experimental biscuit.

\section{Discussion}

In the present study the prebiotic potential of PHGG and FOS incorporated into a biscuit was assessed in thirty-one healthy volunteers. The present study was carried out in a double-blind randomized crossover manner, with volunteers consuming experimental biscuits for $21 \mathrm{~d}$ and placebo biscuits for 21 d. Bifidobacterium spp., Bacteroides spp., Clostridium spp. and Lactobacillus-Enterococcus spp. were enumerated using FISH, and total bacteria were determined using the fluorescent stain 4',6-diamidino2-phenylindole.

The prebiotic nature of FOS has been demonstrated previously in various human volunteer studies (Gibson et al. 1995; Roberfroid et al. 1998), and PHGG has also been shown to have a positive effect on gut motility (Homann et al. 1994; Takahashi et al. 1994). However, there is little information on the ability of specific prebiotics to retain their functionality in final food products. Similarly, previous studies have relied on traditional microbiological culture techniques to monitor changes in gut microflora in response to prebiotics. In view of recent observations relating to the lack of specificity shown by so-called 'selective agars', and the proportion of bacteria in the gut microflora that remain unculturable, direct enumeration of micro-organisms in environmental samples by the use of novel molecular procedures constitutes a significant technological advance (Ward et al. 1992; Amann et al. 1995; Nelson \& George, 1995). 
In the present study consumption of biscuits containing FOS and PHGG gave a significant increase in faecal bifidobacterial numbers $\left(P=2 \cdot 15 \times 10^{-5}\right)$. Bifidobacteria increased from $9 \cdot 18 \log _{10}$ cells/g faeces after the placebo treatment to $9.59 \log _{10}$ cells/g faeces after the experimental treatment. Little or no change in the numbers of total bacteria, Bacteroides spp., Clostridium spp. or Lactobacillus-Enterococcus spp. present in faecal samples collected over the course of the trial was observed. No major changes in bacterial populations were observed on ingestion of the placebo biscuits. In volunteers fed the experimental biscuits during the second treatment period, no significant difference was observed between bifidobacterial populations $7 \mathrm{~d}$ after the end of active treatment and those in pretreatment samples. This finding indicates that the bifidogenesis observed on ingestion of the experimental biscuits did not persist once treatment had ceased. Similarly, in previous prebiotic feeding studies (Roberfroid et al. 1998), increases in the number of faecal bifidobacteria in volunteers fed prebiotics returned to prefeeding levels once prebiotic ingestion had ceased. Such observations illustrate the selective nature of prebiotic fermentation in the colon, and add weight to the concept of beneficial modulation of the gut microflora through dietary supplementation with functional foods. No changes in stool frequency or faecal $\mathrm{pH}$ were observed in the present study. The severity and frequency of reported changes in gastrointestinal symptoms varied greatly between volunteers. In general, ingestion of the experimental biscuits resulted in stools more often described as formed-soft and a reduction in the reported incidence of hard stools and constipation. However, a small increase in abdominal pain, intestinal bloating and flatulence was reported by some volunteers on ingestion of the experimental biscuits. No correlation between the level of increase in faecal bifidobacteria and gastrointestinal symptoms was discerned, however. Bifidobacteria do not produce gas during carbohydrate fermentation and, in the present study, little difference in numbers of clostridia (prolific gas producers) was observed on ingestion of the experimental biscuits. The relationship between numbers of specific bacteria in the gut microflora and gas production is not well understood (Levitt et al. 1995). It is possible that consumption of FOS or PHGG may result in increased gas production, and associated increases in abdominal symptoms, without a concomitant increase in the numbers of the bacterial groups that were monitored in the present study. The relationship between gas economy in the colon, the bacterial species involved and their metabolic response to dietary components, including prebiotics, remains to be clarified.

As noted previously (Roberfroid et al. 1998), a correlation may exist between initial Bifidobacterium spp. population levels and the magnitude of the increase in bifidobacterial numbers observed in the volunteers fed prebiotics. In the present study volunteers showing no response to the experimental biscuits all possessed relatively large populations of bifidobacteria $\left(>9.3 \log _{10}\right.$ cells/g faeces) in pretreatment faecal samples (Fig. 1).

The bifidogenic nature of a final food product containing FOS and PHGG has been demonstrated in the present study. Previous studies in human volunteers have determined the bifidogenic nature of FOS (Gibson et al. 1995; Roberfroid et al. 1998). Gibson et al. (1995) showed that its consumption reduced numbers of Clostridium spp. and Bacteroides spp. as well as increasing numbers of bifidobacteria in human volunteers. No such reductions in numbers of Clostridium spp. or Bacteroides spp. were observed in the present study. Here, we employed a powerful molecular technique (FISH) to enumerate bacteria directly in situ in faecal samples, whereas previous studies have relied on traditional microbiological culture techniques. Selective agars rely on differing growth characteristics of different bacterial groups. However, it is becoming clear that phylogenetically unrelated bacterial species often share phenotypic traits, allowing them to grow on purportedly 'selective' agars (Woese, 1987; Nelson \& George, 1995). FISH, on the other hand, allows the enumeration of bacteria that are closely related at the phylogenetic level. Thus, in order to elucidate the effects of FOS on clostridia and bacteroides populations in the human gut microflora, it may be necessary to use a number of different molecular and microbiological culture-based techniques.

Bifidobacteria have long been regarded among the beneficial members of the human gut microflora. One aspect is the improved health benefits associated with the bifidobacteria-dominated gut microflora of breast-fed infants (Campbell \& Jones, 1996; Vanderhoof \& Young, 1998). High numbers of bifidobacteria are also seen as positive for adult health. Bifidobacteria have been shown to inhibit the growth of pathogenic bacteria, to modulate the immune system, to produce digestive enzymes, to repress the activities of rotaviruses and to restore the microbial integrity of the gut microflora following antibiotic therapy or antibiotic-associated diarrhoea (Bernet et al. 1993; Gibson \& Wang, 1994; Saavedra et al. 1994, Collins \& Gibson, 1999; McCracken \& Gaskins, 1999). Application of prebiotic ingredients to food products conducive to the modern way of living (e.g. biscuits and cereals) has the potential to improve the gastrointestinal health of the population as a whole. However, it is on the health of specific groups of individuals with lowered bifidobacterial numbers in their gut microflora that prebiotic foods may have the greatest impact. These groups may include the elderly, individuals undergoing antibiotic therapy or those with antibiotic-associated diarrhoea and individuals with persistent gastrointestinal conditions, such as inflammatory bowel disease or gastroenteritis. In the present study we have shown that healthy volunteers with lower initial bifidobacterial populations in faecal samples displayed the largest increases on consumption of prebiotic-containing biscuits. Similar observations have been made previously with FOS and inulin (Roberfroid et al. 1998). Thus, prebiotic biscuits containing PHGG and FOS may prove efficacious for increasing bifidobacterial numbers in the gut microflora of those individuals with lowered colonic bifidobacterial numbers. However, welldesigned placebo-controlled and, at least, double-blind clinical trials are required to determine any health benefits associated with increased gut bifidobacterial numbers in such groups as patients with inflammatory bowel disease and hospitalized elderly patients at risk of nosocomially and antibiotic-acquired diarrhoea. 


\section{Acknowledgements}

The present study was carried out with the aid of Novartis Nutrition Research AG, 3176 Neuenegg, Switzerland. The authors would like to thank Dr R. Black, Dr M. Beer and Dr M. Olesen (Novartis Nutrition Research AG) for their assistance and expert input.

\section{References}

Alam NH, Meier R, Sarker SA, Bardhan PK, Fuchs GJ, Schneider H, Mahalanabis D \& Gyr K (1997) Efficacy of a soluble fibre supplemented oral rehydration solution (ORS) in the treatment of acute diarrhoea in children. Gastroenterology 112, 2 Abstr.

Amann RI, Ludwig W \& Schleifer K-H (1995) Phylogenetic identification and in situ detection of individual microbial cells without cultivation. Microbiology Reviews 59, 143-169.

Ames JM, Wynne A, Hofmann A, Plos S \& Gibson GR (1999) The effect of a model melanoidin mixture in faecal bacterial populations in vitro. British Journal of Nutrition 82, 489-495.

Andersson HB, Ellegård LH \& Bosaeus IG (1999) Nondigestibility characteristics of inulin and oligofructose in humans. Journal of Nutrition 129, 1428S-1429S.

Bernet M-F, Brassart D, Neeser J-R \& Servin AL (1993) Adhesion of human bifidobacterial strains to cultured human intestinal epithelial cells and inhibition of enteropathogen-cell interactions. Applied and Environmental Microbiology 59, 4121-4128.

Bouhnik Y, Kouroche V, Achour L, Attar A, Salfati J, Pochart P, Marteau P, Flourié B, Bornet F \& Rambaud J-C (1999) Short chain fructo-oligosaccharide administration dose-dependently increases fecal bifidobacteria in healthy humans. Journal of Nutrition 129, 113-116.

Campbell H \& Jones I (1996) Promoting breastfeeding: a view of the current position and a proposed agenda for action in Scotland. Journal of Public Health Medicine 18, 406-414.

Collins MD \& Gibson GR (1999) Probiotics, prebiotics and synbiotics: approaches for the nutritional modulation of microbial ecology. American Journal of Clinical Nutrition 69, $1052 \mathrm{~s}-1057 \mathrm{~s}$.

Conway PL (1995) Microbial ecology of the human large intestine. In Human Colonic Bacteria: Role in Nutrition, Physiology and Pathology, pp. 1-24 [GR Gibson and GT Macfarlane, editors]. Boca Raton, FL: CRC Press.

Ducluzeau R (1989) Role of experimental ecology in gastroenterology. In Microbial Ecology and Intestinal Infections, pp. 1-5 [E Bergogne-Berezin, editor]. Paris: Springer.

Franks AH, Harmsen HJM, Raangs GC, Jansen GJ, Schut F \& Welling GW (1998) Variations of bacterial populations in human faeces measured by fluorescent in situ hybridization with group-specific $16 \mathrm{~S}$ rRNA-targeted oligonucleotide probes. Applied and Environmental Microbiology 64, 3336-3345.

Fuller R \& Gibson GR (1997) Modification of the intestinal microflora using probiotics and prebiotics. Scandinavian Journal of Gastroenterology 32, 28-31.

Gibson GR (1998) Dietary modulation of the human gut microflora using prebiotics. British Journal of Nutrition 80, S209-S212.

Gibson GR, Beatty ER, Wang X \& Cummings JH (1995) Selective stimulation of bifidobacteria in the human colon by oligofructose and inulin. Gastroenterology 108, 975-982.

Gibson GR \& Beaumont A (1996) An overview of human colonic bacteriology in health and disease. In Gut Flora and Health Past, Present and Future. International Congress and Symposium Series 219, pp. 3-11 [AR Leeds and IR Rowland, editors]. London: The Royal Society of Medicine Press Ltd.

Gibson GR \& Roberfroid MB (1995) Dietary modulation of the human colonic microflora - introducing the concept of prebiotics. Journal of Nutrition 125, 1401-1412.

Gibson GR \& Wang X (1994) Regulatory effects of bifidobacteria on the growth of other colonic bacteria. Journal of Applied Bacteriology 77, 412-420.

Gibson GR, Williams A, Reading S \& Collins MD (1996) Fermentation of non-digestible oligosaccharides by human colonic bacteria. Proceedings of the Nutrition Society 55, 899-912.

Harmsen HJM, Elfferich P, Schut F \& Welling GW (1999) A 16S rRNA-targeted probe for detection of lactobacilli and enterococci in faecal samples by fluorescent in situ hybridization. Microbiol Ecology in Health Disease 11, 3-12.

Holzapfel WH, Haberer P, Snel J, Schillinger U \& Huis in't Veld JHJ (1998) Overview of gut flora and probiotics. International Journal of Food Microbiology 41, 85-101.

Homann HH, Kemen M, Fuessenich C, Senkal M \& Zumtobel V (1994) Reduction in diarrhoea incidence by soluble fibre in patients receiving total or supplemental enteral nutrition. Journal of Parenteral and Enteral Nutrition 18, 486-490.

Hudson MJ \& Marsh PD (1995) Carbohydrate metabolism in the colon. In Human Colonic Bacteria: Role in Nutrition, Physiology and Pathology, pp. 61-73 [GR Gibson and GT MacFarlane, editors]. Boca Raton, FL: CRC Press.

Langendijk PS, Schut F, Jansen GJ, Raangs GW, Kamphuis GR, Wilkinson MHF \& Welling GW (1995) Quantitative fluorescent in situ hybridization of Bifidobacterium spp. with genus-specific 16S rRNA-targeted probes and its application in faecal samples. Applied and Environmental Microbiology 61, 3069-3075.

Levitt MD, Gibson GR \& Christl SU (1995) Gas metabolism in the large intestine. In Human Colonic Bacteria: Role in Nutrition, Physiology and Pathology, pp. 131-154 [GR Gibson and GT MacFarlane, editors]. Boca Raton, FL: CRC Press.

McCracken VJ \& Gaskins HR (1999) Probiotics and the immune system. In Probiotics: A Critical Review, pp. 85-111 [GW Tannock, editor]. Wymondham: Norfolk: Horizon Scientific Press.

MacFarlane GT \& Gibson GR (1997) Carbohydrate fermentation, energy transduction and gas metabolism in the human large intestine. In Gastrointestinal Microbiology, vol 1, pp. 269-318 [RI Mackie and BH Placebo, editors]. London: Chapman and Hall.

Manz W, Amann R, Ludwig W, Vancanneyt M \& Schleifer K-H (1996) Application of a suite of 16S rRNA-specific oligonucleotide probes designed to investigate bacteria of the phylum cytophaga-flavobacter-bacteroides in the natural environment. Microbiology 142, 1097-1106.

Nelson GM \& George SE (1995) Comparison of media for selection and enumeration of mouse fecal flora populations. Journal of Microbiology 22, 293-300.

Okubo T, Ishihara N, Takahashi H, Fujisawa T, Kim M, Yamamoto T \& Mitsuoka T (1994) Effects of partially hydrolyzed guar gum on intestinal microflora and its metabolism. Bioscience Biotechnology and Biochemistry 58, $1364-1369$.

Roberfroid MD, Van Loo JAE \& Gibson GR (1998) The bifidogenic nature of chicory inulin and its hydrolysis products. Journal of Nutrition 128, 11-19.

Saavedra JM, Bauman NA, Oung I, Perman JA \& Yolken RH (1994) Feeding of Bifidobacterium bifidum and Streptococcus thermophilus to infants in hospital for prevention of diarrhoea and shedding of rotavirus. Lancet 344, 1046-1049.

Steer T, Carpenter H, Tuohy K \& Gibson GR (2000) Perspectives on the role of the human gut microbiota in health and methods of study. Nutrition Research Reviews 13 229-254.

Suau A, Bonnet R, Sutren M, Godon J-J, Gibson GR, Collins MD \& Doré J (1999) Direct analysis of genes encoding 16S rRNA from complex communities reveals many novel molecular 
species within the human gut. Applied and Environmental Microbiology 65, 4799-4807.

Takahashi H, Yang SI, Hayaski C, Kim M, Yamanaka J \& Yamamoto T (1994) Influence of partially hydrolyzed guar gum on constipation in women. Journal of Nutritional Science and Vitaminology 40, 251-259.

Tannock GW, (editor) (1999) A fresh look at the intestinal microflora. In Probiotics: A Critical Review, pp. 5-14 Wymondham, Norfolk: Horizon Scientific Press.

Vanderhoof JA \& Young RJ (1998) Use of probiotics in childhood gastrointestinal disorders. Journal of Pediatric Gastroenterology and Nutrition 27, 323-332.

Ward DM, Bateson MM, Weller R \& Ruff-Roberts AL (1992) Ribosomal RNA analysis of microorganisms as they occur in nature. Advances in Microbial Ecology 12, 219-286.
Wilson KH \& Blitchington RB (1996) Human colonic biota studied by ribosomal DNA sequence analysis. Applied and Environmental Microbiology 62, 2273-2278.

Woese CR (1987) Bacterial evolution. Microbiology Reviews 51, 221-271.

Ziemer CJ \& Gibson GR (1998) An overview of probiotics, prebiotics and synbiotics in the functional food concept: perspectives and future strategies. International Dairy Journal 8, 473-479.

Zoetendal EG, Akkermans ADL \& De Vos WM (1998) Temperature gradient gel electrophoresis analysis of $16 \mathrm{~S}$ rRNA from human faecal samples reveals stable and hostspecific communities of active bacteria. Applied and Environmental Microbiology 64, 3854-3859. 